\begin{tabular}{c}
\hline KEMAS 15 (3) (2020) 303-308 \\
Jurnal Kesehatan Masyarakat
\end{tabular}

\title{
Screening for Hypertension and Electrocardiography (ECG) for Cardiovascular Diseases Risk
}

Desy Armalina ${ }^{\bowtie}$, Bambang Witjahjo, Neni Susilaningsih, Ratna Damma Purnawati, Akhmad Ismail, Fanti Saktini

Histology Departement Medical Faculty, Universitas Diponegoro, Indonesia

\begin{tabular}{l} 
Article Info \\
\hline Article History: \\
Submitted February 2019 \\
Accepted December 2019 \\
Published March 2020 \\
\hline Keywords: \\
Elderly, Hyperten- \\
sion, ECG, CVD \\
\hline DOI \\
https://doi.org/10.15294/ \\
kemas.v15i3.17969
\end{tabular}

\begin{abstract}
ECG is a routine, accessible, inexpensive, and non-invasive tool for diagnosis of CVD and has been commonly described in medical reports as a suitable diagnostic tool for assessing 'silent' heart disease. An observational descriptive study, in Gisikdrono Urban Communities, found $72 \%$ elderly with hypertension, and higher than the reported national prevalence in 2013 (25.8\%). We gained 38\% of elderly with abnormal ECG which is: $5 \%$ Old myocardial infarction, 3\% IMO Anteroseptal, 5\% LVH, $8 \%$ LAD, 3\%) of Inferior Ischemia, 3\% dysrhythmia, and 13\% bradycardia, without complaint of heart disease before. Aging became one of the factors of declining protection in the heart and increases the risk of destruction of heart failure. Considering examination of other organs that can affect the cause of heart anomalies to the elderly and expected to raise awareness of the importance of maintaining the blood pressure.
\end{abstract}

\section{Introduction}

According to the United Nation in the World Population Prospects, there will be a substantially increasing number of elderly population internationally. During 2000-2015, the number of elderly population was enlarged nearly 50\% from 607 million to 901 million in 2015, and in 2030 the number of elderly population would predict almost $60 \%$ (Sekplin A.S. Sekeon and, Angela F.C. Kalesaran, 2017). Due to continuously low fertility levels, lower mortality and higher life expectancy rates, in 2013, an elderly in Indonesia population was eight percent of the total population and predicted to increase to more than 80 million individuals by 2050 or 25 percent of the total population (Priebe and Howell, 2014). It makes Indonesia have the foremost number of elderly among other Southeast Asian countries and universally was rank at the top 5 (Sekplin A.S. Sekeon and, Angela F.C. Kalesaran, 2017).
Indonesia is facing a 'health transition' in which the most widespread diseases among the elderly are chronic, non-infectious illnesses, and injuries instead of acute infectious diseases (Cao and Rammohan, 2016). Some chronic conditions among the elderly population such as hypertension, heart diseases, stroke, kidney diseases, cancer, lung diseases, and joint diseases.

Hypertension is one of the important conditions in cardiovascular disease (CVD) and it is prevalent both in developed and developing countries. (Sekplin A.S. Sekeon and, Angela F.C. Kalesaran, 2017) Hypertension is increasing in prevalence with the aging of populations worldwide and is frequently associated with hypertensive heart disease. (Wachtell and Okin, 2016), the higher the blood pressure, the greater the chance of heart attack, stroke, and kidney diseases. (Lenfant, et.al., 2003) CVD increases from $40 \%$ in men and women 40-59 
years of age, to $70-75 \%$ in persons $60-79$ years of age, and to $79-86 \%$ among persons 80 years of age or older (Wilcox and Hirshkowitz, 2009), and leading causes of death among the elderly (Wang \& Zuhlke, 2016).

Electrocardiography (ECG) is a routine, accessible, inexpensive, and non-invasive tool for diagnosis of CVD and has been commonly described in medical reports as a suitable diagnostic tool for assessing silent heart disease (Khane, Surdi, and Bhatkar, 2011). Previous studies have reported that abnormalities on ECG have been independently related to increased CVD risk (Tamosiunas, et.al., 2019) and many epidemiological studies have shown an association between ECG findings with advancing age and CVD and mortality (Khane, Surdi, and Bhatkar, 2011).

The urban communities of Gisikdrono are one of the areas of the west district in Semarang. Gisikdrono has a total area of 105,7 hectares, with the northern boundary is urban communities of Tawangsari, the eastern boundary is urban communities of Bongsari, the southern is urban communities of Manyaran, and urban communities of Kalibanteng Kulon in the west, with a total population of 21,952. These urban communities have regularly maintained activities for elderly integrated health posts but some of the tests that may be required by the elderly have not been carried out.

Method

We used observational descriptive study. Our study conducted in hamlet (RW) 1, Gisikdrono Urban Communities, west Semarang district in 2017. Fifty-four elderlies have been registered at Gisikdrono Elderly Integrated Health Post. Samples were taken by purposive sampling technique. We got 39 elderlies who met inclusion criteria (60 years of age or more), and exclusion criteria (have no dementia, can speak, able to communicate). Primary data was composed using an interview with the elderly, physical examination and ECG assessment. The researcher reserved the ethics principle of Information for Consent. Informed Consent. Anonymity. Confidentiality. Veracity. and Non-Maleficence. Ethical Clearance was approved by the Research Ethics Committee of Faculty of Medicine, Diponegoro University/
Dr. Kariadi Semarang Hospital, No. 22/EC/FKRSDK/I/2017.

Socializeabout theresearch toparticipants of the elderly at Elderly Integrated Health Post was about hypertension, including symptoms, causes, consequences, how to detect, anomalies that may experience due to hypertension and ECG examinations as easy screening of heart anomalies. The implementation of early detection is performed by performing a complete physical examination and an anamnesis in elderly participants, in the $1^{\text {st }}$, and $4^{\text {th }}$ months. In the presence of participants with hypertension, a history of hypertension, the family history with hypertension is recorded and personal consultation is done in private. ECG examination was made in the $4^{\text {th }}$ month. The seminar was made after $5^{\text {th }}$ months.

$\mathrm{BP}$ was measured twice from the right brachial artery with a standard mercury sphygmomanometer in the sitting position after 5 minutes of rest. (Tamosiunas, et.al., 2019) If blood pressure $>140 / 90 \mathrm{~mm} \mathrm{Hg}$ was noted, a third reading was taken after $30 \mathrm{~min}$. The lowest of the three was taken as blood pressure (Khane, Surdi, and Bhatkar, 2011).

Before the recording of the ECG, the whole procedure was explained to the subject. The subject was asked to relax in a supine position. Then, a resting electrocardiogram was recorded in the 12 standard leads, with the calibration of $10 \mathrm{~mm}$ per $1 \mathrm{mV}$ and a paper speed of $25 \mathrm{~mm}$ per second resting in the supine position. All ECGs were recorded between in a cool and calm atmosphere, at room temperature varying from $27^{\circ} \mathrm{C}$ to $30^{\circ} \mathrm{C}$. ECG records were read by 2 independent experienced coders (trained cardiologists) using the 1982 edition of the Minnesota Code (MC)(Tamosiunas, et.al., 2019)

In the $5^{\text {th }}$ months, we socialize the results to all participants, nurses in the district, and we receive $2^{\text {nd }}$ personal consultation. The participants with hypertension or have cardiac anomalies, we recommended for the regular control in the Gisikdrono Community Health Center. The results of the physical examination and ECG were given to Elderly Integrated Health Post as medical records files.

\section{Results and Discussion}

We have implemented the anamnesis, 


\begin{tabular}{l|c|c|}
\hline $\begin{array}{l}\text { Blood Pressure } \\
\text { Classification }\end{array}$ & $\begin{array}{c}\text { SBP } \\
\text { MMHG }\end{array}$ & $\begin{array}{c}\text { DBP } \\
\text { MMHG }\end{array}$ \\
\hline Normal & $<120$ & and $<80$ \\
\hline PreHYPERTENSION & $120-139$ & or $80-89$ \\
\hline $\begin{array}{l}\text { STAGE 1 } \\
\text { HYPERTENSION }\end{array}$ & $140-159$ & or $90-99$ \\
\hline $\begin{array}{l}\text { STAGE 2 } \\
\text { HYPERTENSION }\end{array}$ & $\geq 160$ & or 2100 \\
\hline
\end{tabular}

SBP, systolic blood pressure; DBP, diastolic blood pressure

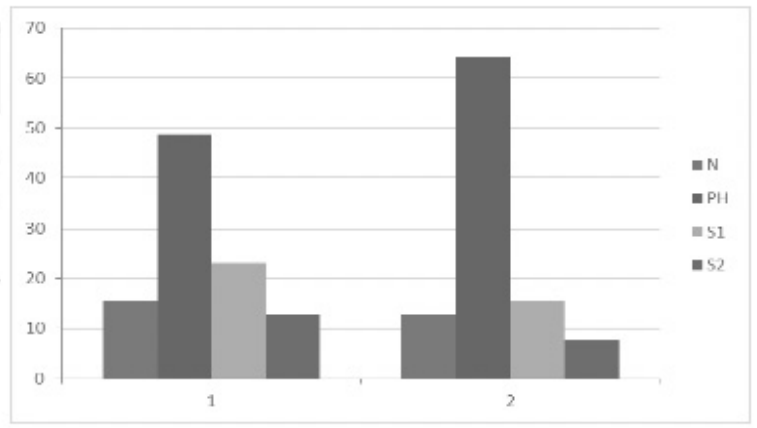

Figure 1. JNC Classification of Hypertension (left). Graphic 1. Blood Pressure Distribution in the elderly (right)

physical examination, ECG and the participants of elders as much as 39 people. We are obtained 15 (38\%) elderly participants with 60-64 years of age, 8 (21\%) elderly with the age of 65-69 years, $4(10 \%)$ elders with age $70-74$ years, 9 (23\%) elders with the age of 75-79 and $3(8 \%)$ elderly people above age 80 years, with the average 69,5 years.

We are obtained $30(77 \%)$ female elders and $9(23 \%)$ of participants male. Indicators of overall health status in Indonesia have improved meaningfully, with life expectancy increasing from 66,3 years in 2000 to 69,1 years in 2015 (World Health Organization, 2017). There was $90 \%$ possibility that life expectancy at birth among South Korean women in 2030 will be higher than 86,7 years, the same as the highest international life expectancy in 2012, and a $57 \%$ probability that it will be higher than 90 years (Kontis, et.al., 2017)

We obtained 9 elderly (23\%) with hypertension or a history of previous complaints and 30 participants (77\%) had no history of hypertension. We obtained 28 participants (72\%) with blood pressure above normal and $11(28 \%)$ with normal blood pressure. Blood pressure examination is in the $1^{\text {st }}$ months with average 132/83 $\mathrm{mmHg}$. After extensive personal examination and consultation, in the $5^{\text {th }}$ months, we got the average blood pressure $127 / 82 \mathrm{mmHg}$. BP should be categorized as normal, elevated, or stages 1 or 2 hypertension according to JNC 7 (Lenfant, et.al., 2003). Vascular risk factors for example hypertension, diabetes mellitus, and dyslipidemia were common in HF patients in all countries, but particularly so in Malaysia (75\%, 67\%, and $52 \%$, respectively) and Singapore $(69 \%, 55 \%$, and $65 \%$, respectively). Smoking was common, with high reported rates in some countries, most notably the Philippines (54\%) and Vietnam (31\%). Rates of renal disease ranged from $4 \%$ in the Philippines to $31 \%$ in Taiwan. Unevenly a fifth of patients had associated atrial fibrillation and more than a tenth had chronic obstructive. (License, et.al., 2016) The difference of prevalence observed among the present study and other studies concerning hypertension and prehypertension could be due to social and cultural differences, dietary and lifestyle factors, and also the age span, as well as the research methodology used (Singh, Shankar, and Singh, 2017).

Distribution Elderly blood pressure according to JNC 7: In the first month elderly with normal BP 6 (15,4\%), 19 (48,7\%) elderly with prehypertension, elderly with stage 1 hypertension 9 (23\%), and 5 (12,8\%) elderly with stage 2 hypertension, in the 5th month elderly with normal BP 5 (12,8\%), 25 (64,1\%) elderly with prehypertension, elderly with stage 1 hypertension $6(15,4 \%)$, and $3(7,7 \%)$ elderly with stage 2 hypertension.

Hypertension was the most noticeable disease (57.6\%) among the elderly population in Indonesia. (Sekplin A.S. Sekeon and, Angela F.C. Kalesaran, 2017) We found that the prevalence of hypertension in this study (72\%) was higher than the reported national prevalence of hypertension based on basic health research in 2013 (25.8\%). The prevalence was also higher than the provincial prevalence of hypertension 
(27.1\%) as reported by Ministry of Health in 2014, Riskesdas 8,7\% in 2016 (Ajeng, 2016), but almost equal with the previous study in Ponorogo 68\% (Cholik Harun Rosjidi, Laily Isro'in, 2017). Raggi reported the prevalence of hypertension in the elderly was $23.1 \%$ in three European countries (Raggi, et.al., 2016) In Sri Lanka, the prevalence of hypertension was $30.6 \%$ and significantly associated with quality of life among the elderly population. (Rathnayake and Siop, 2015), raised blood pressure is the main risk factor for chronic heart disease, stroke, and coronary heart disease. Other than coronary heart disease and stroke, its complications include heart failure, peripheral vascular disease, renal impairment, retinal hemorrhage, and visual loss. It is a silent killer as very rarely any symptom can be seen in its early stages until a severe medical crisis takes place like heart attack, stroke, or chronic kidney disease. Since people are unaware of excessive blood pressure, it is only through measurements that detection can be done. Although the majority of patients with hypertension remain asymptomatic, some people with hypertension report headaches, dizziness, vertigo, altered vision, or fainting episode (Singh, Shankar and Singh, 2017). Through the aging process, large arteries thickening can be due to an in endothelial function reduction, which normally opposes contraction of the underlying smooth muscle vasculature and nitric oxide reduction, such reduction is thought to be chiefly the result of an increase in oxidative stress and enlarged endothelial permeability during aging. Age-associated changes also include less flexible, stiffer and the wall thickness of the peripheral arterial vessels throughout the body. Cardiovascular homeostasis may be affected by age over the increased velocity of the pulse wave and ejection time continuation enhancing summation of arterial waves either antegrade or retrograde, leading to an increase of both pulse and systolic blood pressures in aging. Leading to preferring onset and/or progression of vascular damage and enlarged risk of adverse physiological or clinical outcomes, including excessive cardiac workload and oxygen demand, left ventricular hypertrophy, a further function of endothelium may be altered in aging coronary vessels which contributed as coronary risk factors (Nabil Alama, 2017). The two primary factors of hypertension include problems in either hormonal [natriuretic hormone, renin-angiotensin-aldosterone system (RAAS) mechanisms or disorders in electrolytes (sodium, chloride, potassium). the natriuretic hormone causes a rise in sodium concentrations in cells leading to an increase in blood pressure. The RAAS regulates sodium, potassium, and blood volume, which will finally regulate blood pressure in the arteries (blood vessels that carry blood away from the heart). Two hormones involved in the RAAS system contain angiotensin II and aldosterone (Olin and Pharm, 2018)

We retrieved 10 (26\%) elders with a family history of hypertension and 29 (74\%) of participants has no family history of hypertension. The elderly with a family history of hypertension is $26 \%$, lower than the previous study in China was $67.5 \%$, the blood pressure levels were higher with positive family history. Several researchers have found that genetic influences play an important role in hypertension. Patients who had family history of hypertension would have a 2 to 4 fold higher risk of attainment this disease (Liu, et.al., 2015). Another study found that the prevalence of hypertension enlarged with the number of affected families and also found that mothers with hypertension contributed more than fathers, and first-degree relatives with hypertension were related to higher risk of getting hypertension, associated with seconddegree relatives (Tryjanowski, Sparks and Kosicki, 2006).

We obtained 15 (38\%) of the elderly with abnormal ECG and 24 (62\%) with normal result. Abnormalities acquired from ECG are 2(5\%) elderly with OMI (Old myocardial infarction), 1 (3\%) elderly with IMO Anteroseptal, 2 (5\%) of LVH (left ventricular hypertrophy), 3 (8\%) of the LAD (Left Anterior Descending), and 1 (3\%) of Inferior Ischemia, 1 (3\%) of dysrhythmia, and 5 (13\%) bradycardia, without complaint of heart disease before. Aging or older age became one of the factors of declining protection in the heart and increases the risk of destruction of heart failure. (Lakatta, 2012) Heart disorders in old age due to some changes include changes in the structure of the heart, such as the thickness 
of the ventricle, in the case of LVH, alteration of the cardiac function of heart rate disorders, such as decreased protection and other disorders of the organ. (Nabil Alama, 2017) From 50 percent of the heart failure that is diagnosed, 90 percent of which occurred in $>70$ years. The incidence of cardiac insufficiency increased by 10 percent at the age of 80 years or more, and the incidence of death from heart failure 90 percent occurred above the age of 65 years (Lakatta, 2012). LVH, detected either by ECG or ECHO, has long been documented as an influential predictor of serious cardiovascular sequelae. LVH is not only an adaptation to increased hemodynamic load in hypertension, but is also independently related with a greater risk for myocardial infarction, cardiac sudden death, congestive heart failure, and stroke in the general population, as well as in patients with systemic hypertension, coronary heart disease, chronic kidney disease, and atrial fibrillation. (Mulè, et.al., 2016) Hypertrophy is caused by cardiac myocytes enlargement due to adding more sarcomeres. Also, a reduced in several myocyte myocardia and all heart structures become more inflexible with increasing aging. The left ventricle musculature appeared thicker with a slight increase in heart size, and the size of the left ventricle may decrease. Heart rate and cardiac output that was enlarged in response to physical activity are also decreased. Contraction-Excitation of the myocyte showed great changes during increasing aging as long action potential leading to contraction continuation. The prolonged action potential was due to a decrease in the cation uptake. The DNA containing the nucleus appeared larger with membrane invagination and alterations in the size and shape of the mitochondria (Nabil Alama, 2017).

Study in urban population Solapur City the overall prevalence of ECG abnormalities was $38 \%(152 / 400)$. It also found various ECG abnormalities in decreasing order of frequency were LAD, sinus bradycardia, bundle branch block, ST-T wave abnormalities, ventricular hypertrophy, Q/QS pattern, ventricular premature beats, right ventricular hypertrophy and RAD. They also showed a significantly higher occurrence of ECG abnormalities in males than in females. (Khane and Surdi, 2012).
In our study, the percentage of LVH was $5 \%$, higher than the previous $4 \%$ of subjects without significant age or sex differences. (Khane and Surdi, 2012) Moreover, the presence of LV hypertrophy is also a strong predictor of heart failure(Wachtell and Okin, 2016) It has a prevalence of $2 \%$ of the entire population and $10 \%$ of the geriatric population, and it is asymptomatic, undetected, and untreated (Murtagh, et.al., 2012). Among the elderly, the prognostic significance of specific ECG abnormalities is mostly due to the underlying heart disease, although aging alone also appears to induce alterations in the cardiac structure and function (Khane, Surdi, and Bhatkar, 2011).

\section{Conclusion}

Physical examination in elderly integrated health post and obtained as many as 39 participants with 28 participants with hypertension and 15 participants with abnormalities in the ECG. We need to consider the examination of other organs that can affect the cause of heart anomalies to the elderly. The elderly are expected to raise awareness of the importance of maintaining blood pressure because hypertension can lead to the risk of cardiovascular disorders, although there are no symptoms. This is because of hypertension can increase the load flow to the heart. To confirm the presence of cardiac alterations that are no symptoms, the ECG can be done as an initial screening.

\section{References}

Ajeng, T.E., 2016. The Relationship Between NonCommunicable Diseases History, Jurnal Kesehatan Masyarakat, 12(23), pp. 120-130.

Cao, J., \& Rammohan, A., 2016. Social Capital and Healthy Ageing in Indonesia, BMC Public Health. BMC Public Health, 16(1), pp. 1-14.

Cholik, H.R., \& Laily, Isro'in., 2017. Differences In Risk Factor Of Cardiovascular Disease Risk On. Jurnal Kesehatan Masyarakat, 13(10), pp. 69-76.

Khane, R.S., \& Surdi, A.D., 2012. Gender Differences in the Prevalence of Electrocardiogram Abnormalities in the Elderly: A Population Survey in India. Iranian Journal of Medical Sciences, 37(2), pp. 92-99.

Khane, R.S., Surdi, A.D., \& Bhatkar, R.S., 2011. Changes in ECG Pattern with Advancing Age. Journal of Basic and Clinical Physiology and Pharmacology, 22(4), pp. 97-101.

Kontis, V., Bennett, J.E., Mathers, C.D., Li, G., 
Foreman, K., \& Ezzati, M., 2017. Future Life Expectancy in 35 Industrialised Countries: Projections with a Bayesian Model Ensemble. The Lancet, 389(10076), pp. 1323-1335.

Lakatta, J.B.S., 2012. Aging-associated Cardiovascular Changes and Their Relationship to Heart Failure, Heart Fail Clin., 8(1), pp. 143-164.

Lenfant, C., Chobanian, A.A.V, Jones, D.W.D., Roccella, E.E.J., Bakris, G.L., Black, H.R., Cushman, W.C., Green, L.A., Izzo, J.L., Materson, B.J., Oparil, S., \& Wright, J.T., 2003. Prevention, Detection, Evaluation, and Treatment of High Blood Pressure (JNC 7). The Seventh Report of the Joint National Committee on Prevention, Detection, Evaluation, and Treatment of High Blood Pressure (JNC 7), pp. 1206-52.

License, N. I., Reyes, E.B., Ha, J., Firdaus, I., Mohd, A., \& Phrommintikul, A., 2016. Title Heart failure across Asia : Same Healthcare Burden but Differences in Organization of Care. International Journal of Cardiology, 223, pp. 163-167.

Liu, M., He, Y., Jiang, B., Wang, J., Wu, L., Wang, Y., Zhang, D., Zeng, J., \& Yao, Y., 2015. Association between Family History and Hypertension among Chinese Elderly. Medicine (United States), 94(48), pp. 1-6.

Mulè, G., Nardi, E., Guarneri, M., \& Cottone, S., 2016. Electrocardiography for Assessment of Hypertensive Heart Disease: A New Role for an Old Tool, Journal of Clinical Hypertension, 18(9), pp. 843-845.

Murtagh, G., Dawkins, I.R., O’Connell, R., Badabhagni, M., Patel, A., Tallon, E., O'Hanlon, R., Ledwidge, M.T., \& McDonald, K.M., 2012. Screening to Prevent Heart Failure (STOP-HF): Expanding the Focus Beyond Asymptomatic Left Ventricular Systolic Dysfunction. European Journal of Heart Failure, 14(5), pp. 480-486.

Nabil Alama, M., 2017. Aging-Related Changes of the Cardiovascular System, Journal of Health and Environmental Research, 3(2), pp. 27.

Olin, B.R., \& Pharm, D., 2018. Hypertension: The Silent Killer: Updated JNC-8 Guideline Recommendations. Albama Pharmacy Association, pp. 1-8.

Priebe, J., \& Howell, F., 2014. Old-Age Poverty in Indonesia: Empirical Evidence and Policy Options - A Role for Social Pensions, Tnp2K Working Paper 07 - 2014, (March), pp. 1-97.

Raggi, A., Corso, B., Minicuci, N., Quintas, R., Sattin, D., De Torres, L., Chatterji, S., Frisoni, G.B., Haro, J.M., Koskinen, S., Martinuzzi,
A., Miret, M., Tobiasz-Adamczyk, B., \& Leonardi, M., 2016. Determinants of Quality of Life in Ageing Populations: Results from a Cross-sectional Study in Finland, Poland, and Spain. PLoS One, 11(7), pp. 1-17.

Rathnayake, S., \& Siop, S., 2015. Self-rated Health and Its Determinants among Older People Living in the Rural Community in Sri Lanka. IOSR Journal of Nursing and Health Science, 4(6), pp. 39-45.

Sekplin A.S., Sekeon, \& Angela F.C., Kalesaran, G.D.K., 2017. The Association Between Hypertension and Quality of Life Among Elderly: A Population-Based Comparison Study with General Population in Tomohon, Indonesia. Global Journal of Medicine And Public Health, 6(6).

Singh, S., Shankar, R., \& Singh, G.P., 2017. Prevalence and Associated Risk Factors of Hypertension: A Cross-Sectional Study in Urban Varanasi. International Journal of Hypertension. Hindawi, 2017, pp. 1-10.

Tamosiunas, A., Petkeviciene, J., Radisauskas, R., Bernotiene, G., Luksiene, D., Kavaliauskas, M., Milvidait, I., \& Virviciute, D., 2019. Trends in Electrocardiographic Abnormalities and Risk of Cardiovascular Mortality in Lithuania 1986 - 2015. BMC Cardiovascular Disorders, 3, pp. 1-9.

Tryjanowski, P., Sparks, T. H., \& Kosicki, J.Z., 2006. The Relationship between Means and Variances in Avian Reproductive Success between Local Populations of White Stork (Ciconia ciconia): Reply to Moreno and Polo. Population Ecology. BMC Public Health, 48(2), pp. 174.

Wachtell, K., \& Okin, P.M., 2016. An Age-old Test in Old Age: ECG Left Ventricular Hypertrophy and Cardiovascular Outcomes in the Elderly. Journal of Hypertension, 34(11), pp. 21452146.

Wang, H., \& Zuhlke, L.J., 2016. Global, Regional, and National Life Expectancy, All-Cause Mortality, and Cause-specific Mortality for 249 Causes of Death, 1980-2015: A Systematic Analysis for the Global Burden of Disease Study 2015. The Lancet, 388(10053), pp. 1459-1544.

Wilcox, T., \& Hirshkowitz, A., 2009. The Burden of Cardiovascular Disease in the Elderly: Morbidity, Mortality, and Costs. Clin Geriatr Med, 25(4), pp. 563-vii.

World Health Organization., 2017. State of Health Inequality: Indonesia, State of Health Inequality Indonesia. 